\title{
A clinical case of diagnosis of breast cancer in patients with family history of $B R C A$ mutations 1
}

\author{
Marzhan Aitmagambetova ${ }^{1}$, Gaziza Smagulova ${ }^{1}$, Yerbol Bekmukhambetov², Oksana Zavalyonnaya ${ }^{1}$, \\ Anar Tulyaeva ${ }^{1}$
}

${ }^{1}$ West Kazakhstan Marat Ospanov Medical University, Kazakhstan

${ }^{2}$ National Chamber of Health, Esil District, Kazakhstan

\begin{abstract}
Background: The incidence of breast cancer is growing rapidly worldwide (1.7 million new cases and 600,000 deaths per year). Moreover, about $10 \%$ of breast cancer cases occur in young women under the age of 45 . The aim of the study was to report a rare case of BRCA1-mutated breast cancer in a young patient with multiple affected relatives. Breast cancer is due to a genetic predisposition with $B R C A 1$ and $B R C A 2$ representing a significant proportion of families with a very high risk of developing the disease over a lifetime of up to $50-80 \%$.

Case presentation: In this paper we report a case of a 29-year-old woman with a confirmed diagnosis of left breast carcinoma. Conclusions: Mutations of the BRCA1 gene were revealed in the patient, in two of her sisters, brother and brother's daughter. Key words: BRCA mutation; breast cancer; case report; heredity

Rep Pract Oncol Radiother 2021;26(3):463-469
\end{abstract}

\section{Introduction}

Germline mutations in BRCA1 and BRCA2 genes account for genetic predisposition and increased risk of breast and ovarian cancers [1]. Most hereditary breast and ovarian cancers are due to highly penetrant germline $B R C A$ mutations which are inherited in an autosomal dominant fashion. In these patients, there are frequently several generations of women affected with breast cancer (often premenopausal) and in some families' ovarian cancer as well. In addition, other BRCA-associated malignancies, such as prostate, male breast, and pancreatic cancer may also be observed [2]. The Hereditary Breast and Ovarian Cancer (HBOC) syndrome is caused by loss-of-function mutations in the BRCA1 and
BRCA2 genes and explains approximately 16\% of inherited breast cancers [3]. Germline deleterious mutations in BRCA1 (17q11) and BRCA2 (13q12-q13) are associated with a substantially increased risk of breast cancer as compared with the general population, with a cumulative lifetime breast cancer risk of $46-60 \%$ in BRCA1 carriers and $43-55 \%$ in BRCA2 carriers [4-6]. These mutations have a prevalence of $5-10 \%$ in the general breast cancer population and up to $10-20 \%$ in those patients with triple-negative breast cancer (TNBC) [7-9], and they have been suggested to be responsible for approximately half of all hereditary breast and ovarian cancer cases [10]. Couch et al. 1996 reported a total of 254 BRCA1 mutations, 132 (52\%) of which were unique. These represented mutations entered into a database established by

Address for correspondence: Marzhan Aitmagambetova, West Kazakhstan Marat Ospanov Medical University, Maresyev Str., 68, Aktobe, 030000, Kazakhstan, e-mail: smagulovaga85@rambler.ru 
the Breast Cancer Information Core (BIC). A total of $221(87 \%)$ of all mutations or $107(81 \%)$ of the unique mutations are small deletions, insertions, nonsense point mutations, splice variants, and regulatory mutations that result in truncation or absence of the BRCA1 protein. A total of 11 disease-associated missense mutations ( 5 unique) and 21 variants (19 unique) as yet unclassified as missense mutations or polymorphisms had been detected. Thirty-five independent benign polymorphisms had been described. The most common mutations were 185delAG (113705.0003) and 5382insC (113705.0018), which accounted for 30 (11.7\%) and $26(10.1 \%)$, respectively, of all the mutations [11]. Consistent with the role of BRCA1 and $B R C A 2$ in DNA repair, germline mutations in these genes lead to impaired homologous repair of chromosomal double strand breaks, with at least a five-fold reduction in DNA double strand break repair [12]. This, subsequently, predisposes patients to chromosomal instability and leads to unique treatment opportunities, including sensitivity to DNA-damaging agents, ionizing radiation, and poly (ADP-ribose) polymerase (PARP) inhibitors [13-15]. Multiple studies have evaluated neoadjuvant chemotherapy in BRCA-mutated breast cancers, specifically focusing on pathologic complete response (pCR) rates, a known surrogate for clinical efficacy and outcome. A larger observational study evaluating pCR rates in BRCA1-positive breast cancer patients found high rates of $\mathrm{PCR}$ in patients receiving neoadjuvant cisplatin ( $\mathrm{pCR}$ in 10 of 12 patients, $83 \%$ ), substantially higher than pCR rates in BRCA1-mutated breast cancer patients treated with cyclophosphamide, methotrexate, and fluorouracil (CMF, 7\%); doxorubicin and docetaxel (AT, 8\%); or doxorubicin and cyclophosphamide with and without fluorouracil (FAC, 22\%) [16]. Patients with invasive breast cancer caused by hereditary breast cancer syndromes constitute a unique patient population with individualized, rationally targeted systemic treatment options. The most common syndrome leading to an increased risk of breast cancer, BRCA-related breast cancer syndrome, involves harmful germline mutations in BRCA1 and BRCA2. These patients are particularly sensitive to DNA damaging agents such as platinum agents, as well as to PARP inhibitors, which, by blocking the formation of ADP-ribose polymers at the site of single-strand breaks, pre- vent recruitment of DNA damage repair [17]. Other unique therapies tested in BRCA-mutated invasive breast cancer patients include trabectin, given preclinical evidence suggesting specific activity against intact metastatic breast cancer with excisional nucleotide repair or homologous repair by recombination [18], and lurbinectin, which induces double-strand breaks resulting in activity against platinum-resistant tumors and cell lines deficient in homologous recombination [19].

We report a rare case of BRCA1-mutated breast cancer in a young patient with multiple affected relatives.

\section{Case presentation}

Patient A., 29 years old, Asian (Kazakh), housewife. Diagnosed with carcinoma of the left breast STIIIAT2N2M0. Condition after neoadjuvant chemotherapy (neo-PCT) + bilateral radical mastectomy + radiation therapy.

In September 2016, while breast-feeding the fourth child, she independently found a mass in the left breast. Ultrasonography of the mammary glands in one month revealed nodulation with size $26 \times 22 \times 17$ mm. Further PET-CT (Fig. 2) was performed and a conclusion was: Abnormal growth of metabolic activities observed in the lower part of the left breast and lymph nodes of the left axillary region compatible with malignant structure. Local examination at the time of diagnosis: In the left breast in the lower quadrant - a dense, inactive tumor with the size $3 \times 3 \mathrm{~cm}$ and in the left axillary region lymph node $1 \times 1 \mathrm{~cm}$. Right breast and lymph nodes without pathology. Trepan biopsy of the left breast lump was performed. The result of histology was invasive ductal carcinoma of nonspecific type (Fig. 1).

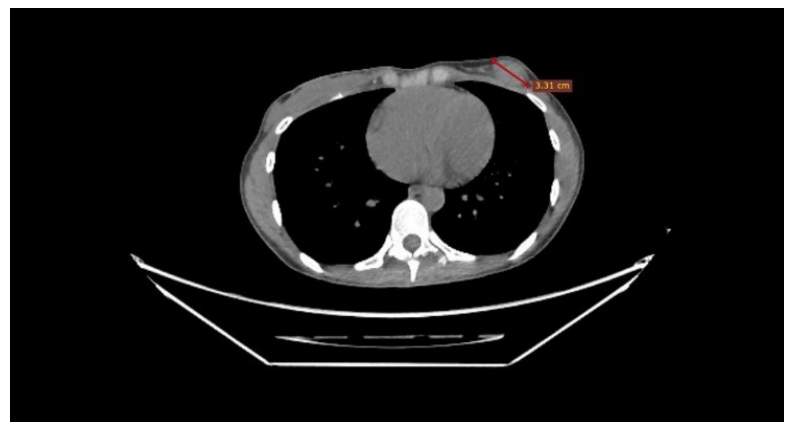

Figure 1. PET-CT of the mammary glands 


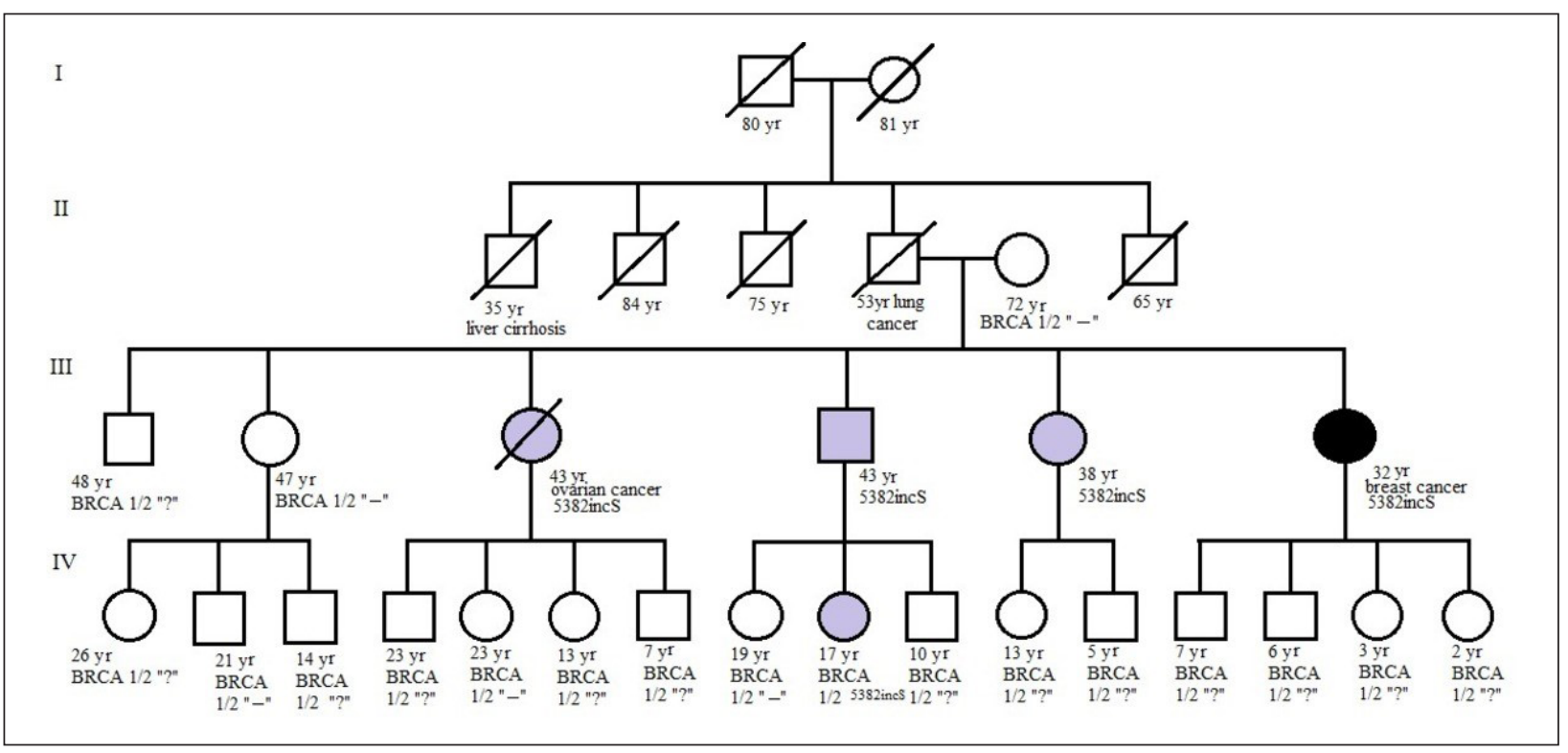

Figure 2. The pedigree of patient under study

\section{Results}

The result of IGH - RE- $0 \mathrm{~B}, \mathrm{RP}-2 \mathrm{~B}$, HER2Neo - negative, Ki $67-60 \%$. The patient received 4 courses of neoadjuvant polichemotherapy (NPCh) with the FEC scheme (dexamethasone $12 \mathrm{mg} \mathrm{I} / \mathrm{V}$ drip to $100 \mathrm{ml}$ physiological saline solution on day 1, epirubicin $138 \mathrm{mg}$ I/V drip to $100 \mathrm{ml}$ physiological saline solution on day 1, fluorouracil $690 \mathrm{mg}$ I/V drip on day 1, cyclophosphamide $690 \mathrm{mg} \mathrm{I/V}$ drip physiological saline solution on day 1). Then the patient received 12 courses of paclitaxel 110 $\mathrm{mg} \mathrm{I} / \mathrm{V}$ per $500 \mathrm{ml}$ of physiological saline solution. After treatment, there was regression. Heredity is burdened. Her older sister died of ovarian cancer at the age of 43 . Her father died of lung cancer at the age of 51 . Pregnancy -4 ; childbirth -4 ; abortion -0 .

Considering the family history, the patient underwent medical genetic counseling with informed consent. Peripheral whole blood was taken in a volume of $10 \mathrm{ml}$. Extraction of DNA from $100 \mu \mathrm{l}$ of peripheral blood was performed using a set of reagents "Proba-GS-Genetics" (NPO DNA-Tekhnologiya, Russia), according to the manufacturer's instructions.

Genotyping was performed by real-time polymerase chain reaction (PCR) using the $B R C A$ OncoGenetics kit (including 8 mutations in the BRCA1 genes (mutations 185delAG, 4153delA, 5382insC,
3819delGTAAA, 3875delGTCT, 300T> G (Cysdel61Gly), 2080 BRCA2 (mutation 6174delT) according to the manufacturer's instructions. PCR was performed using a DTprime detecting amplifier (NPO DNA-Tekhnologiya, Russia).

The study was carried out in a scientific molecular genetic laboratory at the Marat Ospanov West Kazakhstan Medical University . Conclusion: the study of the DNA sample revealed: heterozygous replacement in the $B R C A 1$ gene mutation 5382incS. The patient after chemotherapy treatment had bilateral subcutaneous mastectomy with axillary lymph node dissection. The result of the final histology - fibrosis in both mammary glands, metastases of the axillary lymph nodes were revealed. Then, a postoperative course of radiation therapy on the linear accelerator "Trubeam" on the left breast and the zone of the regional lymph node was given SOD-46 Gr. when the ROD was 2.0 Gr. Considering the presence of a gene mutation (5382incS) in the patient and her family history, medical and genetic counseling of relatives (mother, brother, sisters and their adult children) was carried out, informed consent was obtained from all members of her family. 8 relatives were examined, in whom 3 mutations were identified. The analysis revealed a similar mutation 5382incS in her own older brother (42 years old) and her own daughter (17 years old), her own second older sister (37 years old). The eldest sister, J., 1975 year of 
birth. In October of 2015 she was diagnosed with carcinoma of the ovary STIIIT3N1M0. In November 2018 molecular genetic study of mutation of $B R C A 1, B R C A 2$ genes was carried out. Conclusion: in the studied sample in exon 20 of the BRCA1 gene detected 5382incS mutation in a heterozygous state. Despite the treatment, the therapy was unsuccessful, the patient died on 28.11.2018 at the age of 43 years.

Native second eldest sister, A. born in 1981. Discovered BRCA1 mutation 5382incS. She was examined. According to mammography - BI-RADS M2-L2, breast ultrasound - the lump of the left breast, the size of $1.5-2 \mathrm{~cm}$. A puncture of the mass was done, the result of cytology without atypia. Ultrasound of the pelvis - without pathology. The patient is under the supervision of oncologists.

Older brother (G.) born in 1976. BRCA1 mutation 5382 incS was detected. At the time of the medical examination he had no complaints. Tumor marker PSA $-0.3 \mathrm{ng} \backslash \mathrm{ml}$. MRI of the prostate - MRI picture is typical for nodulation of the right prostate. The patient is under observation.

Niece (brother's daughter) - born in 2002, was similarly examined in January 2019. BRCA1 mutation 5382 insc was detected. According to ultrasound of the pelvis: no structural changes. Breast ultrasound - in the right breast of the upper outer quadrant hypoallergenic formation of $2.0 \times 1.2 \mathrm{~cm}$, similar to the left breast $2.9 \times 1.9 \mathrm{~cm}$. Fibroadenoma of both mammary glands. A puncture of the formation of mammary glands was performed. The result of cytology without atypia. The patient is under observation.

The pedigree was based on the interview of the patient under study; it is impossible to determine the genetic status of deceased ancestors (Fig. 2).

In the presented case, the patient has luminal $B$ type breast cancer. According to TCGA, breast cancer luminal B is characterized by a high TP53 mutation rate $(29 \%)$ and a slightly lower mutation rate of the PIK3CA catalytic subunit alpha (29\%). The main characteristics of genomic, clinical and proteomic subtypes are as follows: mRNA expression - lower ER cluster; high proliferation; DNA methylation - hypermethylated phenotype for a subset; protein expression - less estrogen signaling; high FOXM1 and MYC; reactive RPPA subtypes; DNA mutations - TP53 (32\%); PIK3CA (32\%); MAP3K1 (5\%) [20].

\section{Discussion}

Unlike sporadic cancers, up to $10 \%$ of all cancers are due to hereditary genetic defects. Hereditary cancer was first described by doctors-researchers A. Warthin and H. Lynch, who detected families predisposed to cancer, which, in turn, led to the identification of hereditary cancer syndromes [20]. A number of affected families will inherit one allele of the mutated predisposition gene, called the "germ line mutation", which is hidden in every cell of the body. As a result, hereditary cancers are characterized by 1) early onset cancer, often younger than 50 years at diagnosis compared to an average age of 60 years in the general population, 2) family history of cancer across generations in which cancer types correspond to the tumor spectrum of the syndrome, as confirmed in this clinical case [22]. Our data are consistent with the research of A. Rathore who showed that mutated BRCA carcinoma is found in young people with a family history of the disease [23]. In our case, four out of six children were found to have a mutation in the BRCA1 gene, and two generations were found to have this mutation. One family member died of ovarian cancer. This patient developed the disease at early age. Other family members have a benign formation. However, at the insistence of the family members themselves, we are not talking about the preventive removal of organs. Therefore, they are under careful supervision of oncologists.

Only a relatively small proportion of breast cancers can be explained by the presence of genetic mutations with high penetrance, such as the $B R C A 1$ and BRCA2 genes [24]. Together with mutations in genes of intermediate penetrance, such as $A T M, B A R D 1, P A L B 2$, and CHECK2, they explain $20-25 \%$ of the risk of breast cancer, leaving a significant proportion of heredity that remains to be explained by variants with low penetrance [25]. Undoubtedly, ongoing research into families with multiple cancer-affected members will lead to the identification of other variants in these genes that also predispose to breast cancer [26].

Many genes for different populations have been thoroughly studied [27]. The identified BRCA1 5382ins $C$ mutation in our patient was identified at a frequency of $0.13 \%$ in the Jewish population [28], also found in the population of Austria, Slovenia, Germany, Czech Republic, Greece, Denmark, Po- 
land, Latvia, Lithuania, Belarus and Russia [10]. In Kazakhstan, according to the work of the author B. Apsalikov, out of 250 women, a similar mutation was found in 23. This indicates the occurrence of this mutation in our population [29]. But all this still requires further large-scale research.

In addition, molecular genetic testing is becoming an important tool for predicting drug reactions, as new target therapeutic agents, such as poly inhibitors, appear and platinum-based sensitivity is reported [30]. In our case, the patient was prescribed 12 courses of paclitaxel and there was a significant regression of the tumor, which was confirmed by the instrumental study.

Given that BRCA1 and BRCA2 were identified more than 20 years ago, preventive mastectomy remains the gold standard, mutation carriers have strong preferences for chemoprophylaxis [31]. The patient underwent bilateral subcutaneous mastectomy with lymph node dissection.

The Cancer Genome Atlas (TCGA), a landmark program in the genomics of cancer, has molecularly characterized over 20,000 primary cancers and matched normal samples covering 33 cancers. This collaborative effort between the National Cancer Institute and the National Human Genome Research Institute began in 2006 and brought together researchers from different disciplines and multiple institutions.

Over the next ten years, TCGA generated over 2.5 petabytes of genomic, epigenomic, transcriptomic, and proteomic data. Data that have already improved our ability to diagnose, treat, and prevent cancer [32]. We compared the results of the presented case with the TCGA data. TCGA identified PIK3CA, the alpha catalytic subunit of PI3K, as the most common SMG in breast lumen cancer, occurring at $45 \%$ and $29 \%$ rates in the lumen $\mathrm{A}$ and lumen $B$ subtypes, respectively. Often these are missense mutations that are grouped in the helical domain and the kinase domain of PI3 kinase and are capable of causing cellular transformation when introduced into mammary epithelial cells [33].

The TP53 gene product is a potent tumor suppressor that induces apoptosis or cell cycle arrest in response to cellular stress. A mutation in the TP53 gene is a characteristic feature of basal-like breast cancer. In ER+ breast cancer, TP53 mutation is less common (30\% in lumen B and $12 \%$ in lumen A) [34, 35].

\section{Conclusion}

The national integrated cancer control network (NCCN) has established guidelines for testing $B R C A$ mutations and for treating people who have a mutation in the BRCA $1 \backslash 2$ genes. As our patient has the early age of developing the disease, family history, we used the principles of this guide. NCCN has published recommendations for observing women with positive test for one of the BRCA mutations [31]. Guided by the principle of NCCN, we will observe the relatives of our patient with detected mutations carefully, under strict control.

None declared.

\section{Conflict of interest}

\section{Funding}

The article was written as part of grant funding for a scientific and technical project No. 0118PK01065, the Ministry of Education and Science of the Republic of Kazakhstan and the NAO of the West Kazakhstan Medical University Marat Ospanov.

\section{Author contributions}

Conceptualization, M.A. and G.S.; methodology, Y.B.; software, O.Z.; validation, A.T., O.Z. and Y.B.; formal analysis, G.S.; investigation, M.A.; resources, A.T.; data curation, M.A.; writing - original draft preparation, O.Z.; writing - review and editing, A.T.; visualization, Y.B.; supervision, M.A.; project administration, G.S.; funding acquisition, Y.B. All authors have read and agreed to the published version of the manuscript.

\section{Acknowledgments}

The authors thank the staff of the Medical Center of the West Kazakhstan Medical University named after Marat Ospanov for providing samples of human blood and the Scientific and Practical Center for the technical assistance provided. The article was written as part of grant funding for a scientific and technical project No. 0118PK01065, the Ministry of Education and Science of the Republic of Kazakhstan and the NAO of the West Kazakhstan Medical University Marat Ospanov.

Information pertaining to writing assistance Not applicable. 


\section{Ethical disclosure}

The authors state that they have obtained appropriate institutional review board approval or have followed the principles outlined in the Declaration of Helsinki for all human or animal experimental investigations. In addition, for investigations involving human subjects, informed consent has been obtained from the participants involved.

\section{Consent for publication}

The patients provided written informed consent for the publication of any associated data and accompanying images.

\section{Data sharing statement}

Data will be available on request.

\section{References}

1. Martin AM, Blackwood MA, Antin-Ozerkis D, et al. Germline mutations in BRCA1 and BRCA2 in breast-ovarian families from a breast cancer risk evaluation clinic. J Clin Oncol. 2001; 19(8): 2247-2253, doi: 10.1200/JCO.2001.19.8.2247, indexed in Pubmed: 11304778.

2. Slattery ML, Kerber RA. A comprehensive evaluation of family history and breast cancer risk. The Utah Population Database. JAMA. 1993; 270(13): 1563-1568, indexed in Pubmed: 8371466.

3. Peto J, Collins N, Barfoot R, et al. Prevalence of BRCA1 and BRCA2 gene mutations in patients with earlyonset breast cancer. J Natl Cancer Inst. 1999; 91(11): 943-949, doi: 10.1093/jnci/91.11.943, indexed in Pubmed: 10359546.

4. Chen S, Iversen ES, Friebel T, et al. Characterization of BRCA1 and BRCA2 mutations in a large United States sample. J Clin Oncol. 2006; 24(6): 863-871, doi: 10.1200/ JCO.2005.03.6772, indexed in Pubmed: 16484695.

5. Rich TA, Woodson AH, Litton J, et al. Hereditary breast cancer syndromes and genetic testing. J Surg Oncol. 2015; 111(1): 66-80, doi: 10.1002/jso.23791, indexed in Pubmed: 25381882.

6. Chen S, Parmigiani G. Meta-analysis of BRCA1 and BRCA2 penetrance. J Clin Oncol 2007;25:1329-33. J Clin Oncol. 2007; 25(11): 1329-1333, doi: 10.1200/JCO.2006.09.1066, indexed in Pubmed: 17416853.

7. Hartman AR, Kaldate RR, Sailer LM, et al. Prevalence of BRCA mutations in an unselected population of triplenegative breast cancer. Cancer. 2012; 118(11): 2787-2795, doi: 10.1002/cncr.26576, indexed in Pubmed: 22614657.

8. Kwon JS, Gutierrez-Barrera AM, Young D, et al. Expanding the criteria for BRCA mutation testing in breast cancer survivors. J Clin Oncol. 2010; 28(27): 4214-4220, doi: 10.1200/ JCO.2010.28.0719, indexed in Pubmed: 20733129.

9. Gonzalez-Angulo AM, Timms KM, Liu S, et al. Incidence and outcome of BRCA mutations in unselected patients with triple receptor-negative breast cancer. Clin Cancer Res. 2011; 17(5): 1082-1089, doi: 10.1158/1078-0432. CCR-10-2560, indexed in Pubmed: 21233401.
10. Martin AM, Blackwood MA, Antin-Ozerkis D, et al. Germline mutations in BRCA1 and BRCA2 in breast-ovarian families from a breast cancer risk evaluation clinic. J Clin Oncol. 2001; 19(8):2247-2253, doi: 10.1200/JCO.2001.19.8.2247, indexed in Pubmed: 11304778.

11. Couch FJ, Weber BL. Mutations and polymorphisms in the familial early-onset breast cancer (BRCA1) gene. Breast Cancer Information Core. Hum Mutat. 1996; 8(1): 8-18, doi: 10.1002/humu.1380080102, indexed in Pubmed: 8807330.

12. Moynahan ME, Pierce AJ, Jasin M. BRCA2 is required for homology-directed repair of chromosomal breaks. Mol Cell. 2001; 7(2): 263-272, doi: 10.1016/s1097-2765(01)00174-5, indexed in Pubmed: 11239455.

13. Welcsh PL, Owens KN, King MC. Insights into the functions of BRCA1 and BRCA2. Trends Genet. 2000; 16(2): 69-74, doi: 10.1016/s0168-9525(99)01930-7, indexed in Pubmed: 10652533.

14. Patel KJ, Yu VP, Lee $\mathrm{H}$, et al. Involvement of Brca2 in DNA repair. Mol Cell. 1998; 1(3): 347-357, doi: 10.1016/s10972765(00)80035-0, indexed in Pubmed: 9660919.

15. Gowen LC, Avrutskaya AV, Latour AM, et al. BRCA1 required for transcription-coupled repair of oxidative DNA damage. Science. 1998; 281(5379): 1009-1012, doi: 10.1126/science.281.5379.1009, indexed in Pubmed: 9703501.

16. Byrski T, Gronwald J, Huzarski T, et al. Pathologic complete response rates in young women with BRCA1-positive breast cancers after neoadjuvant chemotherapy. J Clin Oncol. 2010; 28(3): 375-379, doi: 10.1200/JCO.2008.20.7019, indexed in Pubmed: 20008645.

17. Livraghi L, Garber JE. PARP inhibitors in the management of breast cancer: current data and future prospects. BMC Med. 2015; 13: 188, doi: 10.1186/s12916-015-0425-1, indexed in Pubmed: 26268938.

18. Delaloge S, Wolp-Diniz R, Byrski T, et al. Activity of trabectedin in germline BRCA1/2-mutated metastatic breast cancer: results of an international first-in-class phase II study. Ann Oncol. 2014; 25(6): 1152-1158, doi: 10.1093/annonc/mdu134, indexed in Pubmed: 24692579.

19. Balmaña J, Cruz C, Garber J, et al. Lurbinectedin (PM01183) activity in BRCA1/2-associated or unselected metastatic breast cancer. Interim results of an ongoing phase II trial. Cancer Re. 2015; 75 (Suppl 9): P3-13-01, doi: 10.1158/15387445.SABCS14-P3-13-01.

20. Cancer Genome Atlas Network. Comprehensive molecular portraits of human breast tumours. Nature. 2012; 490(7418): 61-70, doi: 10.1038/nature11412, indexed in Pubmed: 23000897.

21. Garber JE, Offit K. Hereditary cancer predisposition syndromes. J Clin Oncol. 2005; 23(2): 276-292, doi: 10.1200/ JCO.2005.10.042, indexed in Pubmed: 15637391.

22. Wang Q. Cancer predisposition genes: molecular mechanisms and clinical impact on personalized cancer care: examples of Lynch and HBOC syndromes. Acta Pharmacol Sin. 2016; 37(2): 143-149, doi: 10.1038/aps.2015.89, indexed in Pubmed: 26616728.

23. Pathak A, Rathore A, Ranjan S, et al. BRCA 1 and 2 mutations in carcinoma breast: An Indian study. Clin Cancer Invest J. 2018; 7(3): 97, doi: 10.4103/ccij.ccij_9_18.

24. Daly MB, Pilarski R, Berry M, et al. NCCN Guidelines Insights: Genetic/Familial High-Risk Assessment: Breast and Ovarian, Version 2.2017. J Natl Compr Canc Netw. 2017; 
15(1): 9-20, doi: 10.6004/jnccn.2017.0003, indexed in Pubmed: 28040716.

25. Sapkota Y. Germline DNA variations in breast cancer predisposition and prognosis: a systematic review of the literature. Cytogenet Genome Res. 2014; 144(2): 77-91, doi: 10.1159/000369045, indexed in Pubmed: 25401968.

26. Skol AD, Sasaki MM, Onel K. The genetics of breast cancer risk in the post-genome era: thoughts on study design to move past BRCA and towards clinical relevance. Breast Cancer Res. 2016; 18(1): 99, doi: 10.1186/s13058-0160759-4, indexed in Pubmed: 27716388.

27. Nik-Zainal S, Davies H, Staaf J, et al. Landscape of somatic mutations in 560 breast cancer whole-genome sequences. Nature. 2016; 534(7605): 47-54, doi: 10.1038/ nature17676, indexed in Pubmed: 27135926.

28. Janavičius R. Founder BRCA1/2 mutations in the Europe: implications for hereditary breast-ovarian cancer prevention and control. EPMA J. 2010; 1(3):397-412, doi: 10.1007/ s13167-010-0037-y, indexed in Pubmed: 23199084.

29. Apsalikov B, Manambaeva Z, Ospanov E. BRCA1 and TP53 Gene-Mutations: Family Predisposition and Radioecological Risk of Developing Breast Cancer. Asian Pac J Cancer P. 2016; 17(8): 4059-4062, doi: 10.14456/apjcp.2016.214/ APJCP.2016.17.8.4059.
30. Kaufman B, Shapira-Frommer R, Schmutzler RK, et al. Olaparib monotherapy in patients with advanced cancer and a germline BRCA1/2 mutation. J Clin Oncol. 2015; 33(3): 244-250, doi: 10.1200/JCO.2014.56.2728, indexed in Pubmed: 25366685.

31. Kotsopoulos J. Mutations and Breast Cancer Prevention. Cancers (Basel). 2018; 10(12), doi: 10.3390/cancers10120524, indexed in Pubmed: 30572612.

32. National Cancer Institute at the National Institute of Health. The Cancer Genome Atlas Program; 2020. https:// www.cancer.gov/about-nci/organization/ccg/research/ structural-genomics/tcga (17 October 2020).

33. Zhang $H$, Liu G, Dziubinski $M$, et al. Comprehensive analysis of oncogenic effects of PIK3CA mutations in human mammary epithelial cells. Breast Cancer Res Treat. 2008; 112(2): 217-227, doi: 10.1007/s10549-007-9847-6, indexed in Pubmed: 18074223.

34. Shangary S, Wang S. Targeting the MDM2-p53 interaction for cancer therapy. Clin Cancer Res. 2008; 14(17): 53185324, doi: 10.1158/1078-0432.CCR-07-5136, indexed in Pubmed: 18765522.

35. National Comprehensive Cancer Network. NCCN Guidelines ${ }^{\circledR}$ \& Clinical Resources. Genetic Familial High-Risk Assessment: Breast and Ovarian. Version 2. 